\title{
SOBRE LOS DENOMINADOS «OSCULATORIOS»: A PROPOSITO DE DOS EJEMPLARES CONQUENSES
}

\author{
ANGEL FUENTES DOMÍNGUEZ
}

Hace más de 110 años nacieron a la literatura científica los denominados «osculatorios" de la mano de D. Aureliano Fernández Guerra en un modesto artículo que daba a conocer los de Mendoya de Sobrado, Orense y Fuentes de Año, Avila (1). Desde entonces se han venido prodigando los hallazgos de nuevos ejemplares de distintas procedencias hasta sobrepasar la cincuentena. A pesar de ello el camino recorrido en orden a la resolución de los múltiples enigmas que sobre su origen y uso se han venido acumulando en todo este tiempo, es desoladoramente más corto que el de su crecimiento numérico.

Recientemente hemos tenido la ocasión de estudiar el grupo más definido de piezas, perteneciente a las denominadas "Necrópolis del Duero" y, con ello, renovado nuestro interés por estos objetos que ya conocíamos desde hacía tiempo gracias al estudio de los dos que se conservan en el Museo de Cuenca. Uno de ellos es inédito y el otro, aunque publicado, bien merece que nos fijemos de nuevo en él pues contiene elementos que modifican sustancialmente su interpretación y como consecuencia la de sus restantes congéneres.

\section{Catálogo}

Ejemplar N. 1. Remate de "Osculatorio". (fig. 1, n. ${ }^{\circ}$ 1)

Procede de las excavaciones que se hicieron en el Cerro de la Muela (Carrascosa del Campo) (2), uno de los principales yacimientos tardorromanos conquenses. Elaborado en bronce fundido, tan sólo se conserva el extremo distal en una longitud máxima de 25,3 $\mathrm{mm}$. y un ancho máximo de $32 \mathrm{~mm}$.

El vástago, del que se conserva el arranque, tenía $4 \mathrm{~mm}$., de diámetro y el grosor máximo de las figuraciones no sobrepasa los $6 \mathrm{~mm}$. Estas consisten en dos aves

(1) Fernández Guerra, A.: «Sobre los osculatorios hallados en Mendoya de Sobrado (Orense) y Fuentes de Año (Avila)", en La Ilustración Católica, 1874.

(2) Excavaciones llevadas a cabo por una misión arqueológica canadiense y publicadas por Sadek, M. "Excavaciones en el Cerro de la Muela, Carrascosa del Campo (Cuenca)", en N.A.H., Ar. 4, 1976. 
de bulto redondo, casi con seguridad palomas, de un ancho máximo de $15 \mathrm{~mm}$. y una altura variable, $9 \mathrm{~mm}$. la derecha y 10,6 la izquierda. Ambas figuras están afrontadas y unidas a la altura de las patas por un doble arco unido a un plinto que descansa directamente sobre el vástago del objeto.

Ejemplar $N^{\circ}{ }^{\circ}$ 2. "Osculatorio". (fig. $1, \mathrm{n}^{\circ}{ }^{\circ}$ 2)

Pieza completa encontrada en las excavaciones del Teatro de Segóbriga (3). Su longitud total alcariza los $128 \mathrm{~mm}$., de los cuales la anilla representa 25, con una sección de 3 . El remate, por su parte, alcanza los $20 \mathrm{~mm}$. de longitud, una anchura de 20,5 y un grosor máximo de 2,7 $\mathrm{mm}$. La sección del vástago es de $5 \mathrm{~mm}$..

Está elaborado, como el anterior, en bronce fundido. Consta de un vástago cilíndrico, sin resalte central, acabado, en un extremo por una anilla, reforzada en su unión con el vástago y decorada con incisiones someras que producen el efecto de molduras muy sumarias. El otro extremo, el correspondiente al remate del objeto, es aplanado y en la actualidad tiene un contorno estrellado con perforación central. No obstante se reconoce fácilmente una antigua figuración enmascarada y perdida. Se trataba de dos figuras de aves, quizás palomas, afrontadas, decoradas de incisiones en el lomo y dispuestas en una percha o cuerpo inferior triangular con hendiduras en los ángulos exteriores de su base; a la manera del doble arco del ejemplar anterior. En un momento dado la figuración fue recortada y limada quedando como hoy la vemos.

\section{Estudio}

Son ya abundantes los ejemplares de "osculatorios" conocidos, aparte de estos dos objeto de nuestra atención. En Galicia el ya citado de Codos de Larouco en Mendoya de Sobrado, en León se conoce un molde de Cacabelos que estuvo en la colección de Schulten según testimonio de Taracena. De Castilla la Vieja hay un grupo muy numeroso, algunos de cuyos ejemplares aparecieron en las Necrópolis del Duero; los cuatro ejemplares de Simancas, de las tumbas 26, 32, 44 y 138; uno de superficie de San Miguel del Arroyo, también los hay en Suellacabras y en Las Merchanas y se cita uno posible de Los Tolmos que no parece que lo sea (4).

(3) Losada, H. y Donoso, R.: Excavaciones en Segóbriga, E.A.E., 43, 1965; donde se dice a propósito de él: “... osculatorio hispano-visigodo en bronce, con anillo y parte central de sección circular. El anillo va decorado con líneas paralelas por su parte exterior. La pieza es en su zona inferior aplanada...", pág. 55.

(4) Para Simancas, vide Rivera Manescau, S.: “La Necrópolis visigoda de Simancas", en B.S.A.A., XIII-XXI, 1936-39.

Para San Miguel del Arroyo, la descripción en Palol Salellas, P.: “La Necrópolis tardorromana de San Miguel del Arroyo. Un conjunto de necrópolis del Valle del Dueron, en B.S.A.A., XXIV, 1958.

Para las Merchanas, vide Maluquer de Motes Nicolau, J : "Excavaciones arqueológicas en el Castro de las Merchanas (Lumbrales, Salamanca)", en Pyrenae, 4, 1968.

Para Suellacabras, Taracena Aguirre, B.: "Excavaciones en algunos lugares de la Provincia de Soria", en M.J.S.E.A., 75, 1924-25.

Para Los Tolmos, vide Jimeno Martínez, A.: "Aportación al estudio de las Necrópolis del Duero, Los Tolmos, Caracena (Soria)", en Rey Invest., 1, 1979. 


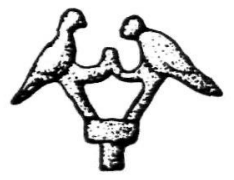

1

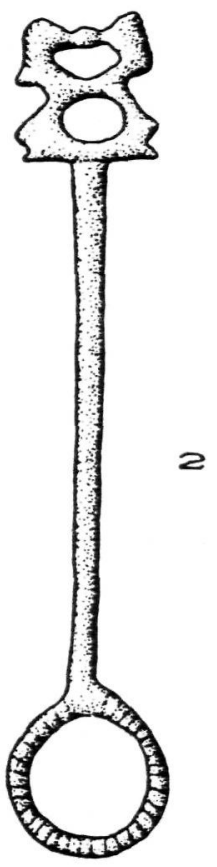

FIG. 1.-Osculatorios de Cuenca: 1, de Carrascosa; 2, de Segóbriga

Aparte hay que contar con los de Osma, Clunia y Valladolid, uno de Palencia con remate troncopiramidal, otro de Valladolid o Palencia del mismo tipo y otro más de Termancia (5); uno con remate de paloma de Paredes de Nava, otro más palentino igualmente con remate figurado de paloma; uno de Clunia, otro de Coria (Cáceres) y otro de Mérida con paloma. En Mérida se encontró otro más con una figura de gallo como remate. En Javier, Navarra, se halló otro con paloma, como el de Cudón, conservado en el Museo de Comillas, Santander. En Ordejón de Arriba aparecieron sin embargo dos palomas afrontadas y en Briviesca, Burgos, un remate peculiar; un delfín (6). Dos palomas enfrentadas hay igualmente en un "osculatorio" de Bílbilis y del mismo yacimiento procede otro que tiene una figuración que podría tratarse de una pareja más de estas aves, aunque no es claro (7). De

(5) Vide Aragoneses, M. J.: "Artes menores previsigodas: anillas con astil de remate troncopiramidal", en R.A.B.M., LIX, 1953.

(6) Alvarez Ossorio, F.: “Amuletos conocidos por "osculatorios" romano-cristianos de bronce hallados en España", Madrid, 1929.

(7) Martín Bueno, M.: "Dos “osculatorios”' procedentes de Bílbilis (Calatalud)", en Pyrenae, 11, 1975, págs. 161 y ss. 
Mallorca conocemos una pieza más, rematada con dos cabezas humanas y hallada en Pollentia (8); también al área mediterránea pertenece el de Portella (Castellón).

En la Meseta Sur se conocen dos más aparte de los descritos por nosotros. Uno proviene del yacimiento de la Torrecilla, Getafe (Madrid), esta vez con remate de una sola paloma (9); y otro más también con figuración de paloma encontrado en Fernán Caballero (Ciudad Real) (10). Incluso en Andalucía se han encontrado, como atestigua el fragmento de Montefrío (Granada) (11).

Tras este breve y resumido catálogo de urgencia queda patente su expansión por prácticamente toda la Península a excepción del área catalana donde al menos por el momento no se conocen. El resto: Galicia, la cornisa norte, León, Castilla, Aragón, Extremadura, Levante, Baleares y Andalucía, muestran, en mayor o menor cuantía, haber conocido estos objetos; si bien el grueso se centra en la Meseta y particularmente en la Norte. En cuanto a sus hallazgos, en su mayoría lo hicieron en contextos dudosos o no determinados. Unos pocos (los ya dichos, Bíbilis, La Torrecilla) provienen de necrópolis y en varios casos se asocian inequivocamente a un contexto urbano; Palencia, Segóbriga, Tiermes, Bílbilis, Clunia, Mérida, Coria, Pollentia, etc.

Básicamente los «osculatorios» tienen todos unas mismas características que siguen fielmente con pocas variantes. Tienen una longitud que oscila entre los $10 \mathrm{y}$ los $23 \mathrm{~cm}$.; aunque a la hora de la verdad las distancias quedan reducidas al mínimo, ya que longitudes como el de Palencia con sus $23 \mathrm{~cm}$. son excepción y la aplastante mayoría tienen longitudes comprendidas entre los 10,5 y $12 \mathrm{~cm}$. minimizándose así las diferencias de tamaño.

Los "osculatorios" tienen tres partes esenciales constitutivas. La anilla inferior, circular; el vástago o astil central y el remate superior. Todo lo demás que puedan presentar es accesorio y no sigue ninguna norma prefijada o al menos nosotros no hemos dado con ella.

La anilla admite pocas variantes y sólo la presencia o ausencia de decoración puede distinguir aparentemente una de otra. En ocasiones, entre la anilla y el vástago hay un cuerpo más o menos complejo, desde un simple rectángulo o molduras más elaboradas o pequeños "plintos" de resabio arquitectónico, como los que se ven en el de la tumba 26 de Simancas entre los segundos y el de la 32 del mismo yacimiento. La función tectónica de tales refuerzos, además de la puramente decorativa que no es desdeñable, pensamos que es la de servir de punto de agarre más seguro entre el vástago y la anilla, un punto flaco de su fabricación y vulnerable a las roturas. Curiosamente (o no tanto si tenemos en cuenta lo dicho) los ejemplares que care-

(8) Arribas, A., Tarradell, M. y Woods, M.: Pollentia II, E.A.E., 98, 1978, pág. 94 y fig. 4.712.

(9) Lucas Pellicer, R.; Alonso Sánchez, M. A.; Blasco Bosqued, C.; Fernández Ochoa, C. y Rubio de Miguel, I.: "Necrópolis romana de La Torrecilla, Getafe (Madrid)", en N.A.H., Arq. 13, 1982, pág. 233 y fig. 12 .

(10) Fernández Ochoa, C. y Caballero Klink, A: «Un nuevo osculatorio procedente de Fernán Caballero, Ciudad Real", en Oretum, 1, 1985, págs. 277 y ss. y fig. 1.

(11) Mergelina, C.: "La Estación arqueológica de Montefrío (Granada)", en B.S.A.A., 12, 1945-46, págs. 15 y ss. y lám. XVI. 
cen de este refuerzo - que son la mayoría - tienen un ensanchamiento de la anilla, que pasa de tener sección circular a la ligeramente triangular como se puede observar en el de tumba 44 de Simancas. O del vástago como se puede ver claramente en el de Getafe, que más que vástago cilíndrico parece troncocónico muy estilizado, al menos por su parte inferior.

Otras veces la solución que dan a este refuerzo es muy ingeniosa, como la de Fernán Caballero que presenta dos bolitas a los lados del vástago. Este sistema nos parece tomado de la orfebrería, donde es normal que las cápsulas del chatón se peguen al aro del anillo así para reforzarlo y también nos evoca las inevitables decoraciones de los broches de cinturón tardorromanos tan difundidos en nuestra Península. Con lo que inevitablemente estamos tras la pista de la metalistería fundida en vigor en la Meseta durante el Bajo Imperio. Mucho más raro es que el refuerzo se haga dividiendo el vástago en dos partes, como están el de Termancia y el de Palencia o Valladolid. En esta ocasión se ponen del lado de las facturas del bronce calado, también con los broches y botones.

El vástago admite pocas variaciones que no sean la longitud. Es una varilla cilíndrica que une anilla y remate. Hay pocos ejemplares en que no tenga sección cilíndrica y sea cuadrada, como en Bíbilis y Pollentia.

En su centro es potestativo que tengan hacia su mitad un resalte. Este resalte, como lo era el refuerzo anterior, es minoritario entre los diversos "osculatorios". El resalte suele ser un simple engrosamiento amigdaloide sin otra ambición; tal y como se puede ver en él los de las tumbas 44 y 138 de Simancas, o puede ser un cuerpo prismático facetado a su vez, a la manera de la talla de una piedra preciosa, como se puede observar en el de Termancia o puede, también, ser solventado con unas simples incisiones que simulan moldurar el fuste del vástago; como está atestiguado en el de remate troncopiramidal de Palencia.

Mucho más raro es que tengan este resalte decorado con motivos florales; como es el caso del de Valladolid-Palencia, donde el nudo al que nos referimos toma forma de capullo abierto de loto (?) y está relacionado constructivamente con el refuerzo de la anilla, creando un diseño complejo y muy elaborado que en la práctica divide en dos mitades el vástago; la inferior conjuntada orgánicamente como describimos y la superior que en nada se diferencia del vástago más pobre por su sencillez.

En algún caso se puede ver otro tipo de decoración en esta parte del uosculatorio" como las molduras que ostenta el de Termancia.

Entre vástago y remate lo normal es que exista un cuerpo, como ocurría con la anilla, de unión. Este cuerpo a menudo es muy ambicioso pues tiende a jugar con el remate para adecuarse armónicamente con él. Tenemos variantes desde el simple plinto que soporta la cabeza de caballo de Simancas, hasta el alto cilindro sobre el que se apoya la paloma de la tumba 138 de Simancas. Cuando los remates son palomas - un porcentaje altísimo, abrumador, de los casos- se opta por varias soluciones; desde subirlas en unas perchas o vástagos menores, a menudo apoyadas en la misma peana (como los ejemplares de Bíbilis o de Segóbriga y Carrascosa del Campo), hasta disponerlas simplemente sobre el vástago, como ocurre con Getafe y Ciudad Real. Otras veces estos vástagos o perchas y la peana conforman 
un cuerpo más complejo y calado, como se puede ver en Segóbriga y se acercan mucho a la concepción de los refuerzos de las anillas.

Donde esta juntura entre vástago y remate adquiere rango de auténtica filigrana técnica y conceptual es en el ejemplar de Pollentia. Aquí el remate es de doble cabeza humana y están dispuestas sobre un pequeño plinto que hace, a su vez, funciones de apoyo de las cabezas a la manera en que se hacen los bustos esculturados. Incluso se insinúa en los cuellos un collar con medallón, logrado con un troquel de circulito de punto central. Es difícil pensar en un efecto tan cálido con tamaño ahorro de elementos y medios.

En cuanto a los remates, básicamente habría que hablar de tres tipos. El mayoritario con cabezas de animales o personas. El pequeño grupo de remates troncopiramidales (sólo cuatro ejemplares) y el más pequeño aún de formas inidentificadas.

En el primero destacan por su importancia el grupo de las palomas, solas o afrontadas. No vale la pena dar el catálogo de todos los «osculatorios» que los presentan, pero son la inmensa mayoría. Aparte de palomas podemos encontrar gallos, como en una de las piezas de Mérida; un caballo, como en Simancas, incluso un delfín, como en Briviesca. Rematados en cabezas humanas se conocen dos ejemplares, el de Suellacabras con una cabeza femenina y el ya citado de Pollentia donde aparecen dos bustos uno femenino y otro masculino; el primero con un peinado de casquete y una diadema o engrosamiento sobre la frente y sienes. Este último ejemplar de Pollentia tiene un marcado regusto constantiniano y participa magistralmente y a escala reducida de toda la expresividad, rigor ideológico y emotividad que traslucen.las representaciones tardorromanas.

El segundo grupo sería el de los remates troncopiramidales. Son los cuatro "osculatorios" que publicó Aragoneses y que efectivamente tienen un cuerpo troncopiramidal, almenado en dos casos y reforzado en los bordes en otro y tres de los cuales tienen perforaciones en sus paredes, simples agujeros cilíndricos o figurando ventanas de medio punto, como en el ejemplar de Termancia. Aparte de que los cuatro pueden provenir de la Meseta Norte (tres seguros y otro de procedencia desconocida), anotemos que plantean un específico problema de uso; más todavía que los restantes.

Finalmente el tercer grupo es el constituído por los remates geométricos o indeterminados. En ellos hay que incluír desde el de Simancas, con un motivo estrellado con perforación central, hasta el conservado en M.A.N. de Madrid, con un simple y pequeño aplastamiento oval en su extremo superior, poco más ancho que el vástago o los de Segóbriga y Bílbilis. Este segundo es claro que remeda torpemente unas figuraciones de aves; el de Segóbriga somos de la opinión que originariamente tenía dos palomas afrontadas y que posteriormente fue recortado de modo que se hizo ininteligible el motivo; con lo que este grupo tercero se reduce notablemente.

Es necesario anotar las semejanzas que los "osculatorios" muestran con otros productos metalisteros tardorromanos. De algunos ya hemos hablado: decoraciones de bolitas, calados, etc. Pero hay más elementos que los aproximan. En cuanto a la manera de estar hechos, todos son fundidos, conocemos además el molde de Cacabelos; pero algunos presentan técnica mixta. Así por ejemplo el de Simancas 
de la tumba 26 tiene el remate aplastado y recortado; de la misma manera que el de Segóbriga, que tiene todo el cuerpo fundido y el remate elaborado recortando la chapa resultante del batido del vástago. Es fácil asociar este sistema a la factura de los recipientes de bronce donde tanto se prodiga el batido, sólo o asociado al fundido.

La decoración suele estar reducida al mínimo fuera de lo ya expuesto. En algunos casos encontramos circulitos de troquel con punto central, como en broches y recipientes. Así está adornado el ejemplar en La Torrecilla y el de Pollentia, donde además el troquel de circulito sirve para hacer el medallón que orna el cuello de los bustos y a la vez se usa para hacer los ojos.

Otro elemento que les acerca a las producciones metalisteras lo tenemos en el "osculatorio" de Tiermes y sus calados simulando una fachada de ventanas, aprovechándose del espacio troncopiramidal. La misma ambición arquitectónica la tenemos reflejada en la decoración de series de arquillos de herradura de las placas de cinturón donde son sumamente características.

Incluso en la selección del repertorio icónico existen paralelos con artes menores. Así la paloma es animal bien conocido en la musivaria tardorromana, aunque en este caso pueda tener algún sentido añadido del que hablaremos a continuación, o el delfín o el caballo de Simancas, en relación con broches, vainas, frenos y atalajes y toda la parafernalia del caballo en la Hispania bajoimperial.

Sobre el uso, origen y significado de estos objetos mucho se ha escrito desde Fernández Guerra sin que por el momento sepamos a qué carta quedarnos definitivamente. Don Aureliano estrenó la lista de quienes veían en ellos signos y objetos de culto cristiano o herético. El embrollo proviene al parecer en un error de catalogación de las papeletas de registro del M.A.N. que relacionaban los "osculatorios" con objetos litúrgicos de la Iglesia Ortodoxa Oriental, Fernández Guerra explicó que eran objetos cristianos y que respondían a unas necesidades litúrgicas muy concretas: sustituir el ósculo que los primeros cristianos se daban entre sí al acabar la Misa para desearse mutuamente la paz y que resultaría ya escandaloso, mediante el ósculo particular de cada uno de ellos al Lapis Pacis, Tabula Pacis o Asser ad Pacem, que serían nuestros «osculatorios». Según Tertuliano desde el 180 se sustituyó este sistema por el beso a la patena, por lo que cronológicamente los objetos en cuestión debían ser anteriores a esta fecha. Independientemente de que pronto esta precisión cronológica fuese desestimada, la explicación de Fernández Guerra hizo fortuna de manera que muchos después la adoptaron y, de hecho, aún hoy les seguimos llamando "osculatorios» (12).

Hasta después de la Guerra Civil predominó la idea de que fuesen sacrificalia o instrumentos litúrgicos. Con el hallazgo de Simancas se empezó a considerar que

(12) Por cierto, pensamos que no se debe cambiar el nombre de estos objetos. Tan difundido está entre todos los investigadores, incluso los menos relacionados con el mundo clásico, que suprimirlo será introducir un factor añadido de equivocación. Además no hay por qué prescindir de más de cien años de historia de la investigación en este campo. Seguramente y como ocurre con otros casos parecidos - entre ellos el muy significativo de "sigillata»-, osculatorio entre comillas podrá ser un término si no correcto, sí al menos definido y de inmediato reconocimiento. 
fuesen símbolos gnósticos, fascina de las sectas agapeta y basilidiana como dijera Rivera Manescau (13), idea ésta inducida sin duda por haberse encontrado en la misma necrópolis un anillo con una posible representación herética de esta clase. Esta opinión de Rivera Manescau sería seguida por Nieto Gallo (14), refiriéndose en particular a los de Simancas y más tarde por Losada y Donoso con el de Segóbriga (15). Mientras tanto el propio Zeiss y Alvarez Ossorio se harían eco de parecidas posturas al respecto (16) destacando simpre el contenido religioso que traslucían los ejemplares conocidos. El primero, buen conocedor del material gótico, destacó el trasfondo romano que parecían evidenciar en su estilo; el segundo se hizo eco de su significado religioso.

Un giro de ciento ochenta grados en la interpretación de los "osculatorios» lo supone el trabajo que les dedicó Taracena (17). Se remontó a la opinión de Fernández Guerra e investigó por su cuenta en la liturgia cristiana oriental, llegando a la conclusión de que no se trataban en realidad de tales objetos de uso religioso y reparando en el origen del error, las papeletas del registro del M.A.N. Por primera vez los relacionó con piezas formalmente similares del sur de Rusia y de Crimea y con el ambiente helénico consustancial a estos hallazgos. Incluso estableció un intento de aproximación a su llegada a nuestra Península desde la Rusia meridional a través de hallazgos intermedios de Bulgaria. También les fijó cronología visigoda (serían objetos venidos de Europa oriental precisamente con los visigodos) aunque no se decidió a darles ninguna utilidad de entre las que por entonces se barajaban.

Tras Taracena, Aragoneses estudiaría los "osculatorios" de remate troncopiramidal para los que sugiere un triple uso; bien sevir de estuche para guardar pequeños objetos incrustados, bien ser portafuegos en ceremonias religiosas - para lo que tendrían las perforaciones en las paredes-, o bien haber servido de tintinabula. No se decide a dar por buena ninguna de las tres; la primera porque efectivamente faltan las incrustaciones; la segunda porque de serlo quedaría por explicar el sentido de los de remate figurado que no podrían serlo de ninguna manera y luego sí que parecen que están ambos íntimamente emparentados; lo tercero porque les falta el engarce para el badajo que habrían de tener. Para Aragoneses los "osculatorios" troncopiramidales pueden tener un exclusivo carácter decorativo basándose en su aparición en enterramientos femeninos y les da una cronología de los siglos IV y V.

Habrá que esperar más de veinte años para que se vuelva a suscitar el interés por estos objetos con el trabajo de Martín Bueno a propósito de dos ejemplares de Bíbilis; uno procedente de excavaciones clandestinas y el otro de los trabajos efectuados en las termas (18). Martín Bueno se basa en ciertas ideas latentes de

(13) Rivera Manescau, S.: Op. cit, págs. 7 y ss.

(14) Nieto Gallo, G.: "Los fondos visigodos del Museo Arqueológico de Valladolid", en M.M.A.P., 1943, págs. 214 y ss.

(15) Losada, H. y Donoso, R: Op. cit., págs. 55 y ss.

(16) Alvarez Ossorio, F.: Op. cit., Madrid, 1929.

(17) Taracena Aguirre, B.: "Sobre los amuletos visigodos en bronce», en A.E. Arq., XIV, 1940-41, págs. 67 y ss.

(18) Martín Bueno, M.: Op. cit., pág. 162. 
trabajos anteriores y llega a la conclusión de que se trata de objetos de tocador femenino, en particular removedores de perfumes y vuelve a las argumentaciones esgrimidas con anterioridad por Aragoneses de que se encuentran en tumbas femeninas y, caso de Simancas, dentro de vasos de cristal.

Más recientemente y a raíz del hallazgo del ejemplar de Getafe, Alonso Sánchez vuelve a retomar el sentido originario de las investigaciones concluyendo que efectivamente son removedores de perfumes y, por lo tanto, objetos de tocador; que su origen hay que buscarlo en objetos helenísticos muy difundidos en el sur de Rusia, donde perviven hasta época romana y que sería en ésta cuando fueran difundidos aquí. Pero además hace por vez primera una explicación sobre su uso. Piensa Alonso Sánchez que servían para mezclar los perfumes y batirlos, para lo cual se usaría de la anilla, cosa que viene apoyada porque en los ejemplares ucranianos conservan en la anilla una pequeña protuberancia que serviría de apoyo. La manera de hacerlo consistiría en hacerlo girar entre las palmas de las manos frotándolas (19).

En un trabajo posterior Alonso Sánchez vuelve sobre el tema y apunta una serie de hechos que creemos aclaran definitivamente muchos aspectos sobre su origen y uso (20). Opina que originariamente estas piezas pudieron ser removedores de perfumes, estudia una serie de manifestaciones inconográficas helenísticas y llega a la conclusión de que eran conocidos en este ámbito como objetos de tocador femenino y como removedores de perfume. En Europa Oriental nunca pasaron de servir para esto, pero en Hispania derivaron hacia objetos de uso paralitúrgico. Por su asociación a los perfumes oleosos, se debieron usar como removedores y aplicadores de óleos consagrados por los cristianos que, de esta forma, echaron mano de un objeto que les era bien conocido por su uso de toilette cuando la Iglesia estaba todavía conformando su liturgia. Los fieles llevarían anualmente óleos a la Misa Crismal que se celebra el Jueves Santo para su bendición y usarían de ellos en caso de enfermedad aplicándolo sobre los órganos enfermos. Tal sería el carácter paralitúrgico propuesto por la Prof. Alonso Sánchez.

Desde luego hay aspectos de esta nueva hipótesis que vienen en apoyo parcialmente de algunas de las teorías expuestas con anterioridad e, independientemente de ello, muestra elementos que casan bien con lo que arqueológicamente conocemos sobre estos objetos.

Desde luego parece claro que estamos ante objetos de tocador, removedores de perfume. Esto ya lo señalaron en parte Aragoneses y Martín Bueno. Ciertamente aparecen en enterramientos femeninos, como es el caso de Simancas donde en su enterramiento 32, del que proviene el "osculatorio" con cabeza de caballo, se halló también una fusayola que indica el sexo femenino de su propietaria y en el mismo una jarra globular de vidrio que nos puede inducir a pensar que fuera el recipiente de perfumes. En el enterramiento 138 se vuelve a repetir la asociación vaso de vidrio (en este caso desconocido) y "osculatorio", asociación que igualmente se re-

(19) Lucas Pellicer, R. et Alii: Op. cit, pág. 235.

(20) Alonso Sánchez, M. A. en un trabajo en este mismo volumen, del que hemos tenido amable acceso al original. 
nueva en el enterramiento 11 de Suellacabras. Parece claro que se trata efectivamente de un instrumento relacionado con los perfumes. Nosotros mismos hemos tenido la ocasión de comprobar estadísticamente esta fuerte asociación entre "osculatorios» y vasos de vidrio al establecer unas matrices de correlación en los ajuares de las Necrópolis del Duero (los recipientes idóneos entre ellos para contener ungüentos). No sería oportuno tratar ahora estas correlaciones, pero apuntemos que sólo en este caso los índices de correlación muestran alguna significación; prueba de su evidente conexión a la manera apuntada. No parece tan claro, empero, que sea sólo objeto de tocador femenino, ya que en algunas ocasiones como en el mismo enterramiento 11 de Suellacabras aparece asociado a una punta de lanza que más parece convenir a una tumba masculina, o en la tumba 138 de Simancas. Su asociación a los perfumes lo convierte en un objeto fundamentalmente femenino, pero no en exclusiva; incluso, según se ve, tiene una circunstancial vinculación funeraria.

Sobre la manera de ser utilizado caben algunas reservas a lo propuesto por Alonso Sánchez de que servirían para batir los perfumes oleosos, cosa que se haría con la anilla. En los removedores de perfumes altoimperiales de vidrio que tienen anilla terminal y por remate un simple botón, parece que ésta era la parte introducida en los vasos para mover y extraer los perfumes; según se deduce de la angostura de la boca del recipiente que no permite otro uso. Así se comprueba claramente en un enterramiento de Xanten donde apareció un removedor de los que decimos con dos ungüentarios o "lacrimatorios» de cuello cilíndrico (21), (fig. 2, n. ${ }^{\circ} 1$ y 2).

De la misma manera pensamos que en los «osculatorios» la parte activa era realmente la del remate. Esto es, que es el remate figurado la parte usada para aplicar o remover y no la anilla. Si el uso de estos objetos es simplemente el de aplicador, ninguno de los extremos parece más idóneo que el otro para tal función. Si, como parece más lógico por su tamaño y morfología, es el de removedor, entonces es el remate figurado el más apto por varias razones. Para empezar es sintomático que en un porcentaje altísimo de los casos éste tenga palomas afrontadas; esto es, dos vástagos que vemos repetidos en el caso de Pollentia, pero con cabezas y que pudieron haber hecho función de palas removedoras, tanto o más efectivas que la anilla. Tampoco faltan ejemplos de "osculatorios" con remates planos, como de Simancas - estrellado - o el de Segóbriga especialmente aptos para batir, o el del M.A.N. con una terminación mínima, como los de vidrio y que nos habla de que la anilla es ajena al funcionamiento concreto del útil, ya que éste último es una verdadera cucharilla. Además no hay que perder de vista los perfumes eran oleosos y por ello sería necesario asegurar la varilla removedora que, lubricada por el aceite, se escurriría frecuentemente. Para ello nada mejor que la anilla. Lo único cierto es que cuando se asocian a vasos de vidrio, los "osculatorios" lo hacen con vasos grandes y abiertos, al menos tanto que caben por igual la anilla y el remate.

Tampoco se debe olvidar que la anilla, independier temente de esa función aseguradora que proponemos, es una herencia de objetos de toilette más antiguos y an-

(21) Charlesworth, A.: "The Xanten Glass", en Beitäge zur Archeologie des Römische Rheinlande, Römischen Ausgrabungen, 23, 4, 1984, lám. 108, un ejemplar y n. ${ }^{\circ} 20$, al ajuar al que aludimos. 


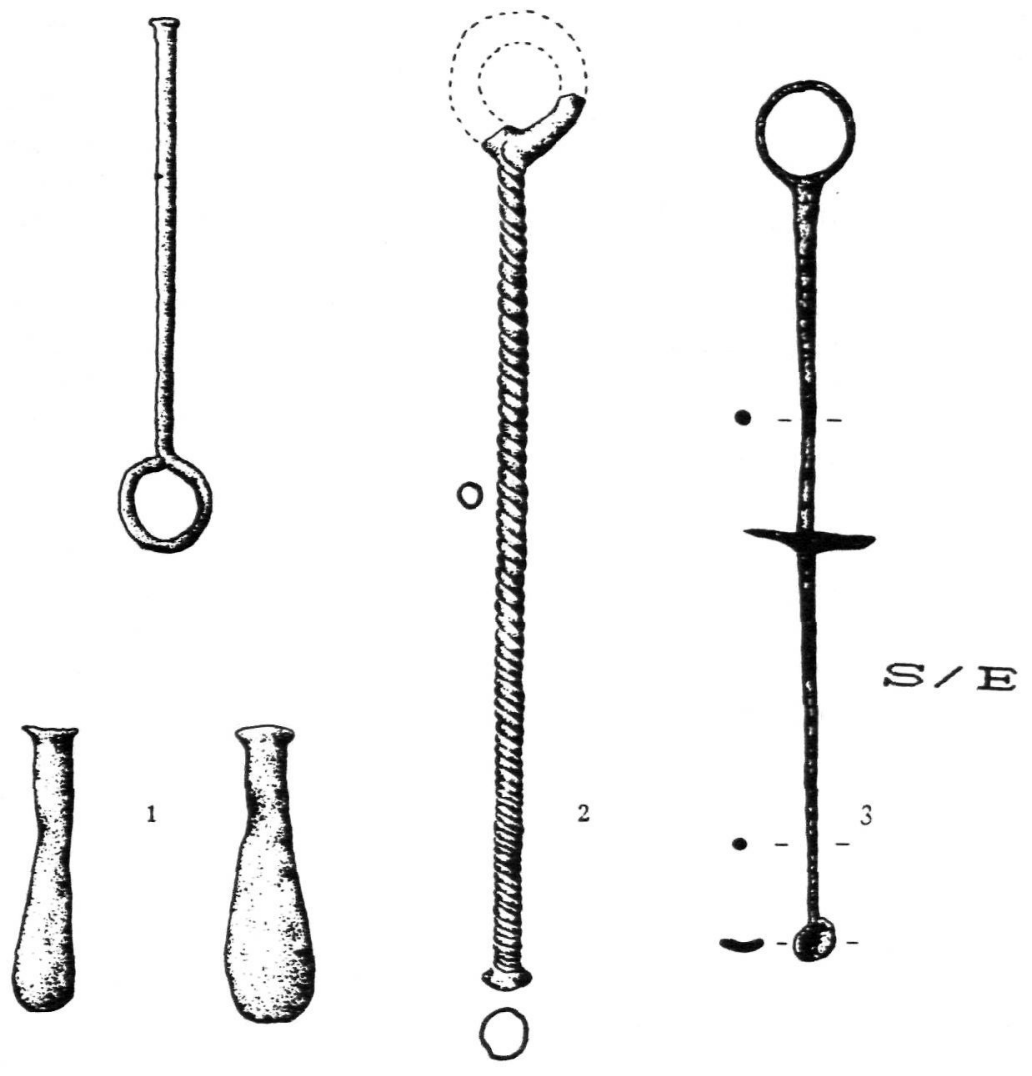

FiG. 2.-N. ${ }^{\circ}$ y 2: Ungüentarios y removedores de Xanten (según Weissberger). N. ${ }^{\circ}$ 3: Removedor chipriota.

tecedentes de nuestros "osculatorios". Ya nos hemos referido a los removedores altoimperiales de vidrio como el de Xanten, con anilla no activa terminal. Otro ejemplo de gran ayuda para comprender esto nos lo brinda un removedor precisamente griego (no se olvide la importancia renovada del mundo helenístico en su génesis), procedente de Chipre y también de bronce, consistente en una varilla rematada en un extremo en una cucharita y en el otro en una anilla (a la manera como aparecen los de vidrio, pero conceptualmente más cercano a nuestros objetos) y en su mitad presenta un disco que sirve para cerrar el ungüentario (22), (fig. 2, n. ${ }^{\circ} 3$ ).

(22) Recogido por Richter, G.: Greek, Etruscan and Roman Bronzes, Nueva York, 1915, vol. II, n. ${ }^{\circ} 871$ y 872 del catálogo, págs. 299 y 300 . También el n. ${ }^{\circ} 1860$ de la pág. 466, igualmente chipriota y extraordinariamente parecido a nuestros "osculatorios". 
Sobre el uso paralitúrgico que propone Alonso Sánchez, poco más podemos añadir. Independientemente de su propia fundamentación; ello vendría a explicar una serie de hechos de difícil comprensión hasta la fecha. Como el que se encuentren por igual en enterramientos femeninos y masculinos y, sobre todo, que los remates figurados tengan obsesivamente por motivos las palomas, simples o afrontadas y que tal y como se quiso tradicionalmente pudieron estar relacionadas con simbología cristiana.

Sobre el origen de estos utensilios quedan algunos puntos por aclarar, a pesar de que parece cada día más evidente que hay que buscarlo en prototipos helenísticos orientales importados en baja época. Nos parece definitiva la argumentación de Alonso Sánchez al respecto y perfectamente documentada. No obstante hay que resaltar lo que todavía ignoramos: cómo y cuándo llegó este préstamo y por qué sólo a Hispania y no a otros puntos del Imperio Occidental.

A título de simple hipótesis sugerimos que se debe tener en cuenta la posibilidad de que exista más de una vía de llegada, aunque el punto de origen sea el mismo. Dado que la raíz helenística es innegable, cabe pensar que el "osculatorio", tal como lo conocemos, sea tanto deudor de los prototipos europeos orientales directamente, como de los removedores de vidrio altoimperiales que, de igual manera, son también herederos suyos. Es decir, que estuviéramos ante un mismo influjo diversificado. El asunto de la anilla según hemos expuesto vendría a fundamentar esta opinión.

Otro problema es explicar por qué sólo existen en nuestra península y no fuera de ella, así como determinar los puntos intermedios entre Oriente e Hispania. Para nosotros es claro que los "osculatorios" son un producto hispánico en exclusiva, al margen de semejanzas circunstanciales o influjos innegables. Ya antes aludimos a una serie de elementos, decorativos y técnicos sobre todo, que los relacionaban con otros productos metalisteros tardorromanos hispánicos y en especial de la Meseta. Pero si atendemos a las facturas sobre todo de bronces contemporáneas, es tanto más evidente cuanto decimos. Son varios los casos de recreaciones de tipos hispánicos en exclusiva a partir de distintos antecedentes. Además de la vajilla de bronce y los adornos personales (botones y broches fundamentalmente), tenemos el caso palmario del denominado "cuchillo de Simancas", un tipo genuinamente hispánico con una génesis seguramente pareja a ésta. El caso de los "osculatorios" es si cabe más interesante ya que testimonia la importancia trascendental que tuvo la metalistería, sobre todo de metales preciosos, tardorromana y especialmente bizantina en nuestra baja Antigüedad y que explica la ausencia de hitos intermedios en Occidente. Nosotros sólo conocemos un caso que se pueda asimilar a uno de nuestros "osculatorios" y procede del sur francés, de la Aquitania, con su remate de figura de gallo (aquí también son conocidos), su peana, su astil, su resalte... todo excepto la anilla (23). Aunque la ausencia de otros ejemplares galos y su proximidad geográfica y conceptual al nutrido y caracterizado grupo hispano abonen más por su

(23) Coupry, J.: «Petit-Bersac (Aquitanie)», en Gallia, 30, 1973, págs. 463-464 y fig. 20, de imprecisa cronología imperial. 
inclusión en éste que por creer en un tipo o variante distinto del que nos ocupa y fuera de nuestra península.

Addendum. Una vez escrito el artículo hemos conocido a través del Prof. Balil Illana un trabajo reciente que vuelve de nuevo sobre algunos objetos de interés para nuestro propósito (WASOWICZ, A. "Deux aspects de l'art funéraire dans les antiquités du Bosphore cimmérien», en Revue du Louvre, 4, 1987, págs. 268 ss.). En él se estudian de nuevo los paralelos citados del área oriental y se propone una nueva identificación como husos domésticos.

Independientemente de la escasa credibilidad de tal atribución, no encontramos en el trabajo argumentos de peso que nos induzcan a reconsiderar nuestras hipótesis. 